\title{
A Review of Online Advertising Effects on the User Experience
}

\author{
Giorgio Brajnik and Silvia Gabrielli \\ University of Udine, Udine, Italy
}

\begin{abstract}
This article reviews empirical research conducted in the last decade on the subject of how online display advertising affects the usability and quality of user experience of websites. In particular, from an in-depth analysis of research questions, methods, and findings of the reviewed studies, the following is discussed: (a) which conceptual and theoretical background knowledge, based on psychological explanations of user cognition, affection and behavior, can best support the design and investigation of online advertising, and (b) which specific adverts features and properties are key to understand and favor certain types of effects on users. By capitalizing on this benchmark knowledge on benefits of adverts and their hidden costs, web researchers and practitioners are encouraged to approach online advertising from a deeper and more comprehensive perspective, which is centered on qualities of web interaction that go beyond traditional usability factors. It is speculated that many of the theories and models developed for advertising effectiveness, and variables used to measure it, could and should be applied also when assessing the quality of the user experience when using websites in general, regardless of whether they contain adverts.
\end{abstract}

\section{INTRODUCTION}

Browsing is a frequent activity a user performs on a website, be it a news site, a blog, or a social network; equally frequent is the exposure of users to online advertisement, which is likely to be the most important revenue source for such a site. Advertisement, however, is also a factor that perturbs browsing processes that visitors engage in. From a user perspective, adverts can both provide additional channels for satisfying informational or emotional needs (57\% of Europeans prefer getting information about products through the Internet and 27\% declared that adverts helped them in deciding what product to buy, according to the Online Publisher Association, 2007), and at the same time make things harder for users. For instance, Gibbs (2008) reported examples of usability problems in news websites due to advertising, such as "causing the user to lose his place and to perceive

We thank AboutUser S.r.L. for funding this project, and an anonymous reviewer for her or his useful suggestions.

Correspondence should be addressed to Giorgio Brajnik, Dip. Di Matematica e Informatica, University of Udine, Via delle Scienze 208, 33100 Udine, Italy. E-mail: brajnik@uniud.it 
the text below the advert as an entirely new story" or users struggling to find the "close" button to get rid of a pop-up advert.

Negative effects of advertising include a wide range of consequences for the quality of the user experience of the website:

1. Low usability may ensue in reading, scanning, and browsing activities.

2. Information seeking tasks may fail to reach success.

3. Users may become confused and tired, and face an increased cognitive load.

4. Users may experience frustration, irritation, and may develop negative affect, emotions, or moods with respect to adverts.

5. Users may develop negative attitudes toward websites hosting the adverts, leading to reduced visit duration, fewer visits, fewer referral chances, increased negative word-of-mouth.

These effects on websites whose revenues depend heavily on advertisement, like online newspapers, would be dramatic in the long term.

The purpose of this article is to present a review of experimental studies carried out in the last decade regarding effects of online advertising on the user experience. More specifically we present:

1. An outline of key research questions addressed by previous empirical studies, their findings and interpretations.

2. A taxonomy of different features of adverts, and the effects that have been experimentally determined on user experience with respect to the hosting website and in terms of consumer response to adverts.

3. A conceptual background of current psychological theories (tested or referred to by reviewed studies) regarding several cognitive phenomena that can explain part of the user behavior.

4. A discussion of why these theories and findings can be relevant to web designers and usability evaluators, beyond web advertising.

We believe that practitioners involved in creating adverts and in allocating them, as well as owners and managers of websites hosting advertisements can learn how to optimize adverts allocation and how to avoid negative effects due to advertising spreading on hosting websites. In addition, researchers willing to investigate these phenomena will be able to find examples of research problems and methods that may be suitable to their specific investigations.

\section{WEB BROWSING AND ONLINE ADVERTISING}

Browsing is a process where information is continuously examined and assessed through rapid and frequent judgments of relevance (Marchionini, 1995). Browsing can be directed, when the target of the search is sharply defined and the process is very systematic; semidirected, when the target is not clearly defined and the process is less systematic; and undirected (or surfing), when there is no specific goal and 
very little focus. Novak, Hoffman, and Duhachek (2003) differentiate goal-directed browsing (i.e., directed and semidirected) from undirected browsing in terms of motivation (extrinsic vs. intrinsic), involvement (situational vs. enduring), benefits (utilitarian vs. hedonic), nature (cognitive and work vs. affective and fun), and type of shopping (planned purchases vs. compulsive or impulse shopping). In fact, a reason people engage in undirected browsing is to fulfill emotional needs, where browsing is often driven by opportunities, curiosity, entertainment. On the contrary, when people use the web for information seeking, they engage in directed or semidirected browsing. Information seeking is "a process where humans purposefully engage in order to change their state of knowledge" (Marchionini, 1995). It takes place because users try to fill gaps in their knowledge, they try to make sense of incomplete and inaccurate knowledge, they look for specific answers or search for known items.

Marchionini (1995) highlighted several limitations of browsing: (a) It poses a high attentional demand on individuals, (b) users have to cope with information overload, (c) it offers plenty of opportunities for distraction through information that is tangential to one's goal, and (d) users may suffer consequences of "cognitive inertia," the tendency to follow available paths of evidence rather than examining alternative or contrary directions.

Because of these limitations, attention scarcity is a major issue when browsing the web. Online advertising exacerbates attention scarcity. First, by providing additional paths of exploration that may turn out to be useful or interesting, especially in goal-free surfing. Second, by providing irrelevant distractions during goal-directed tasks, the risk of failures of the information seeking process also increases.

According to Norman (2003), and indirectly to previous work by Tractinsky (1997), aesthetics of the user interface influences the affective ${ }^{1}$ state of the user, which is positively related with effectiveness and usability. Positive affection promotes an open-minded usage of a website and fosters creative new strategies for problem solving, which tend to lead to higher success levels, in turn improving affection. On the other hand, negative affection leads to more focused and narrower cognitive processes often bringing limited success, increasing anxiety, annoyance, irritation, dissatisfaction, and further intensifying negative affect. We posit that online adverts may amplify such a feedback loop (Figure 1): Online adverts may lead to irritation, triggering therefore such a loop leading to increasing irritation. In addition, when people are focused on problem solving, stress and anxiety due to task difficulties are likely to occur and low success levels may follow. In such situations, online adverts can further increase irritation, leading to a deterioration of performance. Studies by Hartmann, Sutdiffe \& De Angeli (2008) showed that when the scenario of use of a website is serious (typically associated to directed/semidirected browsing), usability has a halo effect ${ }^{2}$

\footnotetext{
${ }^{1}$ Human affective and emotional systems can be ascribed two different functions: the affective system makes unconscious rapid judgments and decides if the current situation is good or bad; the emotional system consciously attributes causes of and explanations to affect states (Norman, 2003).

${ }^{2}$ The halo effect describes the phenomenon by which people associate positive personality traits to attractive individuals and they tend to make more positive judgments on other attributes, like intelligence.
} 


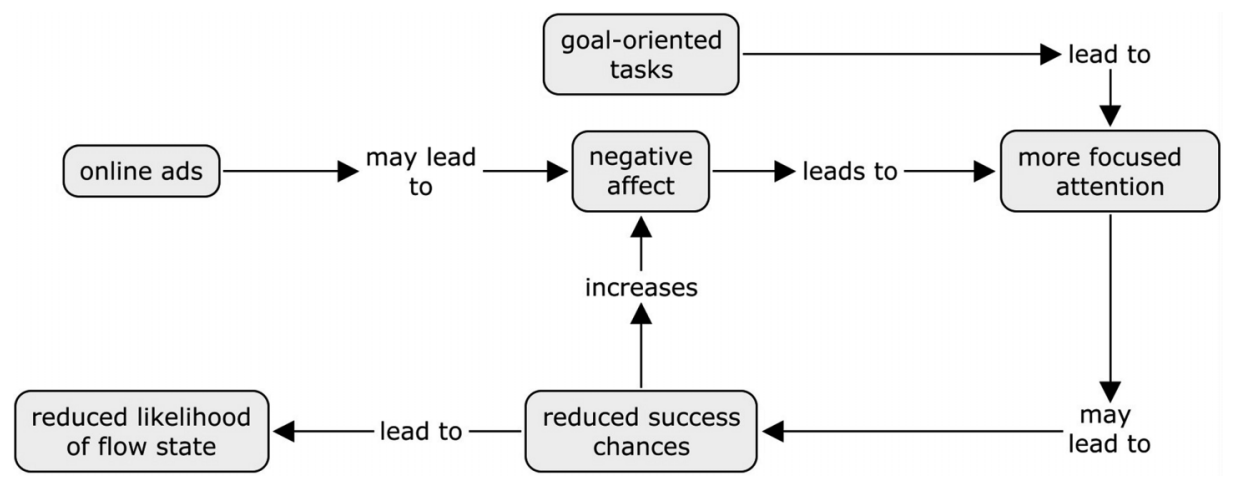

FIGURE 1 The positive feedback loop that increases negative affect.

on content of the site; on the other hand, in less serious conditions (like those typically associated to undirected browsing), aesthetics has a halo effect in overriding negative usability. A possible extrapolation of these results would be that when seriously using a site, low usability levels would not be counterbalanced by positive effects due to aesthetics, with the consequence that negative affection would cause negative attitudes and behavior with respect to website content; this might not happen when people are involved in a less serious undirected browsing scenario. As reminded by Hassenzahl, Schobel, and Trautmann (2008), usability has to be considered for understanding user judgement of design qualities of products and websites when people focus on attainment of do-goals or on presence and absence of negative outcomes. However, if they care about particular psychological needs, such as attaining pleasurable stimulation, hedonic qualities like stimulation, novelty, challenge and identification (the need to express one's self through objects) become more important. This should raise web designers' attention toward the link between a website-specific attributes and context-dependent prioritizations of individual needs and motives (Hassenzahl, 2006).

Another relevant concept is flow, which is "the state in which people are so involved in an activity that nothing else seems to matter; the experience itself is so enjoyable that people will do it even at great cost, for the sheer sake of doing it" (Csikszentmihalyi, 1990, p. 4). Sicilia and Ruiz (2007) enumerated several benefits of flow: increased learning, more exploratory and positive behavior, positive subjective experience, positive influence on intentions to purchase and intentions to return to the site. The flow state is associated to ability to elaborate information shown to the user (elaboration is meant as the amount, complexity, and range of activity triggered by a stimulus): According to one theory, the person is so absorbed by the interaction that information is not elaborated upon; most of the attention is devoted to maintaining an orientation in the site. Another theory hypothesizes that the flow state enhances focused attention on the task, leading to high levels of concentration and involvement. 
The observational study described by Novak et al. (2003) found that flow state occurs in both goal-directed and undirected browsing, even though when people are goal directed they are more likely to recall actual situations where flow occurred to them (i.e., their perception of flow state improves). The observational experiment carried out by Sicilia and Ruiz (2007) confirms that flow is associated to better attitudes toward the website, that it enhances the ability to process information that is relevant to the task, but that it does not affect positive beliefs about brands/products included in web pages. Intense flow states are more likely to enhance favorable information processing, suggesting that sparse information and straightforward descriptions are not optimal. In fact, heterogeneous or irrelevant information could lead to interruptions and distractions, preventing the establishment of a flow state. This is the danger of online advertising: It might distract the user from the task, lowering the likelihood of establishing the flow state, and hence reducing the user ability to process the information; another reason why user performance may degrade.

\section{ONLINE DISPLAY ADVERTISING}

Branding and direct sales are the reasons why a company pays for online advertising. Branding tries to increase the perceived value of a product/company to the customer; a direct sale advert tries to persuade the consumer to act immediately, by clicking the advert, placing a telephone call, or doing other activities. Three important adverts measurement and pricing models are the exposure model, where advertisers pay for impressions ${ }^{3}$ and adverts are priced according to the cost-per-thousand (cost-per-mille) or a flat rate for a given period; the interaction-based model, which assumes that advertisers pay each time a user interacts with or clicks the advert, and adverts are priced according to the click-through rate ${ }^{4}$; and the outcome-based model, according to which advertisers pay for performances based on lead generation, online inquiries, registrations, referrals, orders, or purchases. Although outcome is the ultimate goal of direct sale campaigns, this latter model has two major drawbacks: It disregards any branding goal, and it does not consider that revenues for publishers depend also on the quality of the advert, a factor that is not under their control (Shen, 2002). This fact holds also for the interaction-based model.

Currently used adverts show a large range of features, many of which have important effects on advert efficacy and on user performance in using the publishing website. Some features of adverts are intrinsic, that is, they can be determined from the advert independently from where it is located or how it appears during

\footnotetext{
${ }^{3}$ The Internet Advertising Bureau UK (2004, p. 5) defines impression as "a measurement of responses from an advert delivery system to an advert request from the user's browser, which is filtered from robotic activity and is recorded at a point as late as possible in the process of delivery of the creative material to the user's browser - therefore closest to actual opportunity to see by the user."

${ }^{4}$ Click-through rate is the frequency of clicks on an advert as a percentage of impressions served.
} 
the interaction; other ones are relational, that is, dependent on the context in which the advert is used.

In terms of content type of the advert, Rodgers (2000) mentioned five basic categories: product/service, public service announcement, social issue, corporate, and political. Other intrinsic features include the media used; adverts may be single-medium when a single medium is used (text, static, or animated images) or multimedia, where a combination of different media are used simultaneously (text and/or images and/or sound, often time dependent). Video adverts can be preroll, when they are shown as trailers at the beginning of a content video, or postroll, when they are shown at the end of the main video. Sometimes postroll videos are automatically started only after corresponding overlay adverts are dismissed. Rich media is the catch-all term for adverts enhanced with motion, sound, video, and interactive features.

If the advert is based on images, then relevant features are colors and those mentioned in advertisement standards, like shape and size; see Internet Advertising Bureau UK (2008a) for typical examples of shapes and dimensions. Other intrinsic features include animation of the advert, that the IAB suggests to last no more than $15 \mathrm{~s}$. In a simple solution, animation can be implemented with alternating images, in which case a common choice is to use three repeating frames, which may be considered as a phrase made of simple components constituting a rhythmic structure (waiting, tension, and solution). Adverts can be live, if their content is periodically updated; the advert may be a trick ad, so that it misleads users into thinking it is a widget of the desktop user interface. Adverts may be either user activated or not (like when the audio channel of an advertising starts on page loading). Finally, ads may be interactive, like adverts implemented in Flash, with which users can engage an interaction. Sundar and Kim (2005) discussed the concept of interactive advertising: Interactivity can be viewed from a functional viewpoint, where it is conceptualized as the offered functionalities, described in terms of media used, degree of control given to the user, and kind of communication made available (mono/bidirectional, a/synchronous, etc.). Interactivity can also be viewed from a contingency perspective, a transactional conceptualization that emphasizes messages exchanged between user and system: Each message is contingent upon previous ones and those preceding them, in a threaded manner. Low interactivity in this case is achieved by a page containing all the content at once; a medium interactive level is available when a few links are available to get associated contents; a high interactivity is available when content is further fragmented, and each fragment is individually accessible through more user actions.

Relational properties include the absolute location of the advertising in the page (e.g., in page header, footer, central area, left/right column), relative location with respect to other objects in the page (e.g., an advert located at the end of an article, or below a navigation bar, or adjacent to other competitors' adverts). With respect to the page that hosts the advert, it can be expandable (e.g., when the mouse is rolled over, the advert expands, temporarily covering other elements in the page), it can be a pop-up window (when a temporary window is opened in the foreground), a pop-under window (when a temporary window is opened, but in the background, and is usually noticed only after the user closes all the other windows), an overlay 
(when the advert appears similarly to a new window, obscuring or obfuscating the underlying content, but technically it still is an element of the same browser window). Finally, the advert can be related to user actions, tasks, and goals; it can be an interstitial advert, also known as a splash page, if it appears as a new page usually after a user action; an advert can be repeatedly exposed during a task execution; it can be rotated with other adverts; it can be contextually relevant if its message is relevant to the topic of the page (which is usually the case with textbased adverts).

Certain advert types can interrupt a user task, requiring a specific action to remove it (which usually is the case for pop-ups, pop-unders, interstitials, and overlays). A related aspect, discussed by Li and Leckenby (2004), concerns control ownership, that is who controls exposure of an advert and interaction with it. A pop-up advert is an example of control exerted by the advertiser, because the advert may be exposed without any user action, its interaction may start without any explicit user actions, and it may disappear automatically after a given time elapses.

\section{EXPERIMENTAL STUDIES}

We conducted a literature search to identify experimental studies that in the last decade have investigated the effects of banners, as well as their characteristics, on web user's behavior and attitudes. The search was limited to English language literature and included studies published both in journals and conference proceedings between 1998 and 2008. Electronic searches of the Internet were conducted by using search engines (like Google Scholar) and other scientific literature databases. A qualitative analysis initially based on the abstracts of the papers retrieved was made to select the ones most relevant to our research topics and those providing empirical evidence to support findings. The analysis resulted in 19 studies that met our inclusion criteria. They were compared according to the following categories: research questions addressed, methods applied for the investigations, main results obtained.

Table 1 provides a concise presentation of their contents.

\section{MAIN FINDINGS REGARDING ONLINE ADVERTISING EFFECTS}

Table 2 provides a summary of main effects of online advertising.

\subsection{Theoretical Background}

In the following we revisit some of the main cognitive psychological theories and models that have been applied by the empirical studies reviewed, pointing out their relevance and usefulness as a source of inspiration (as well as explanation) for a deeper understanding of qualities of the web user interaction, even beyond online advertising. 


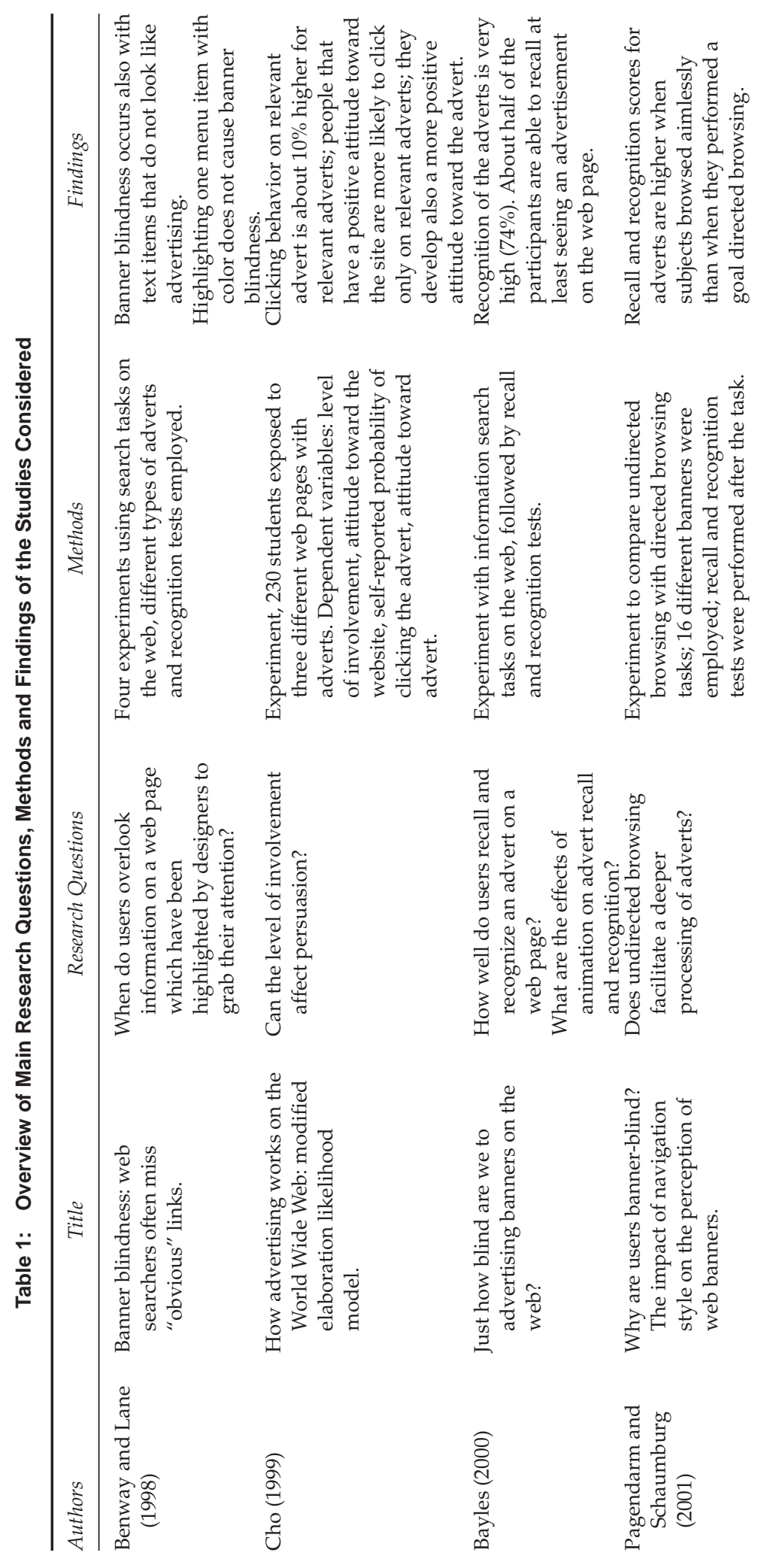



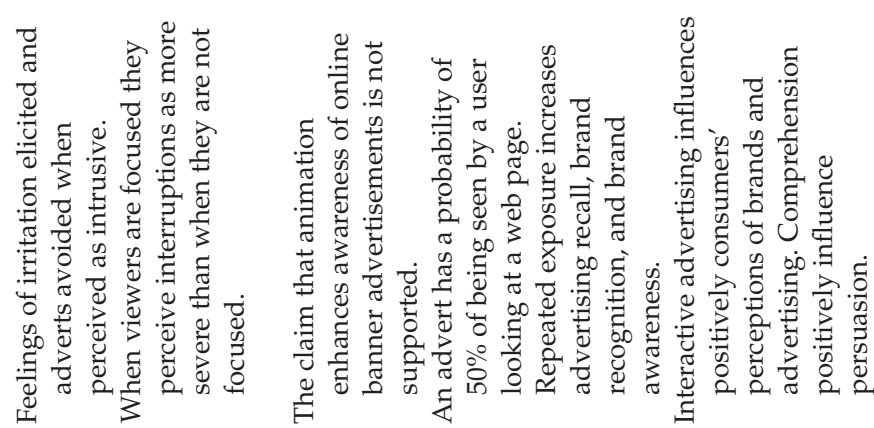

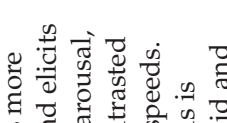

क्षे के

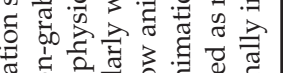
ब

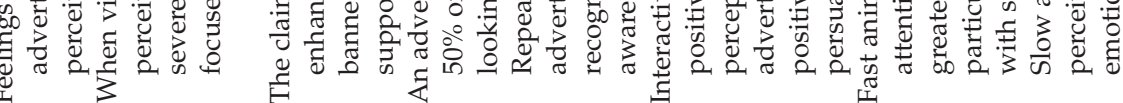

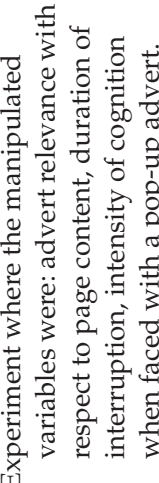
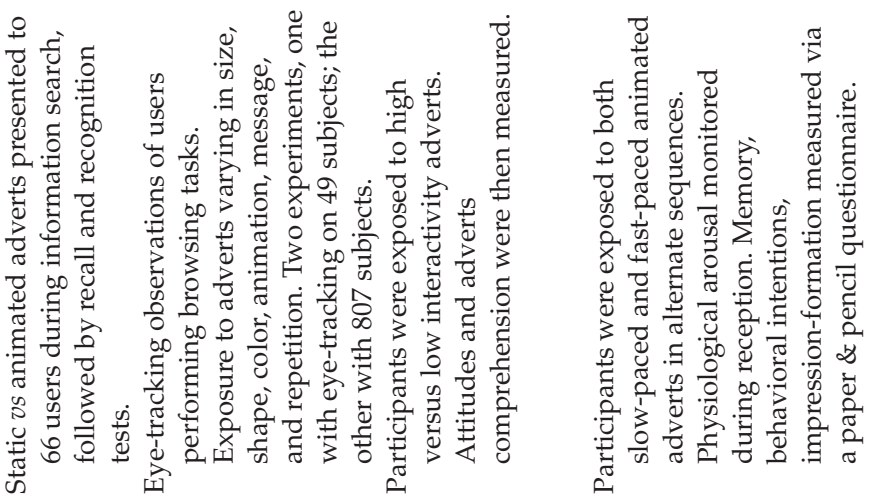

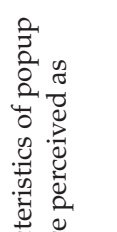

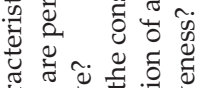

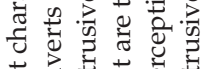

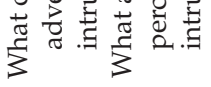

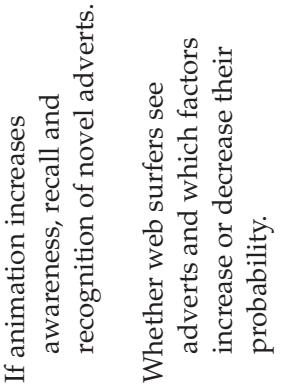

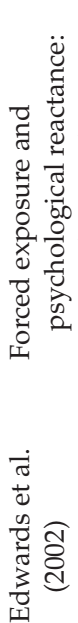

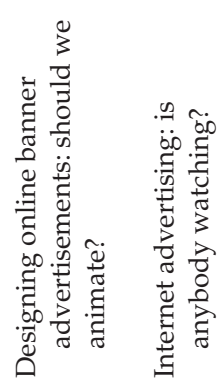

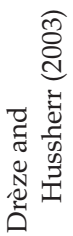
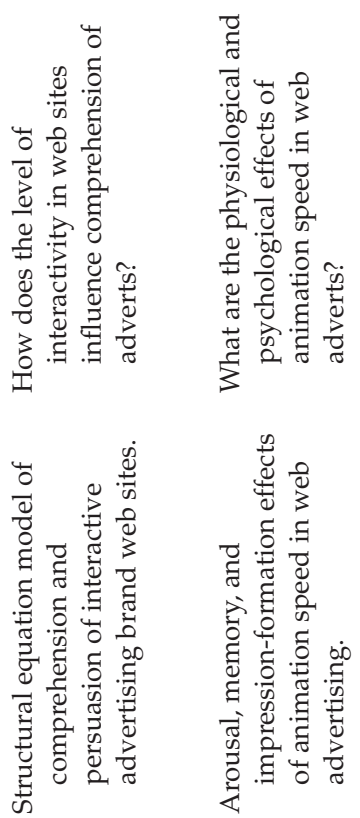

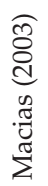

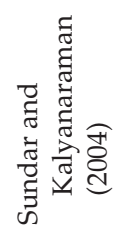



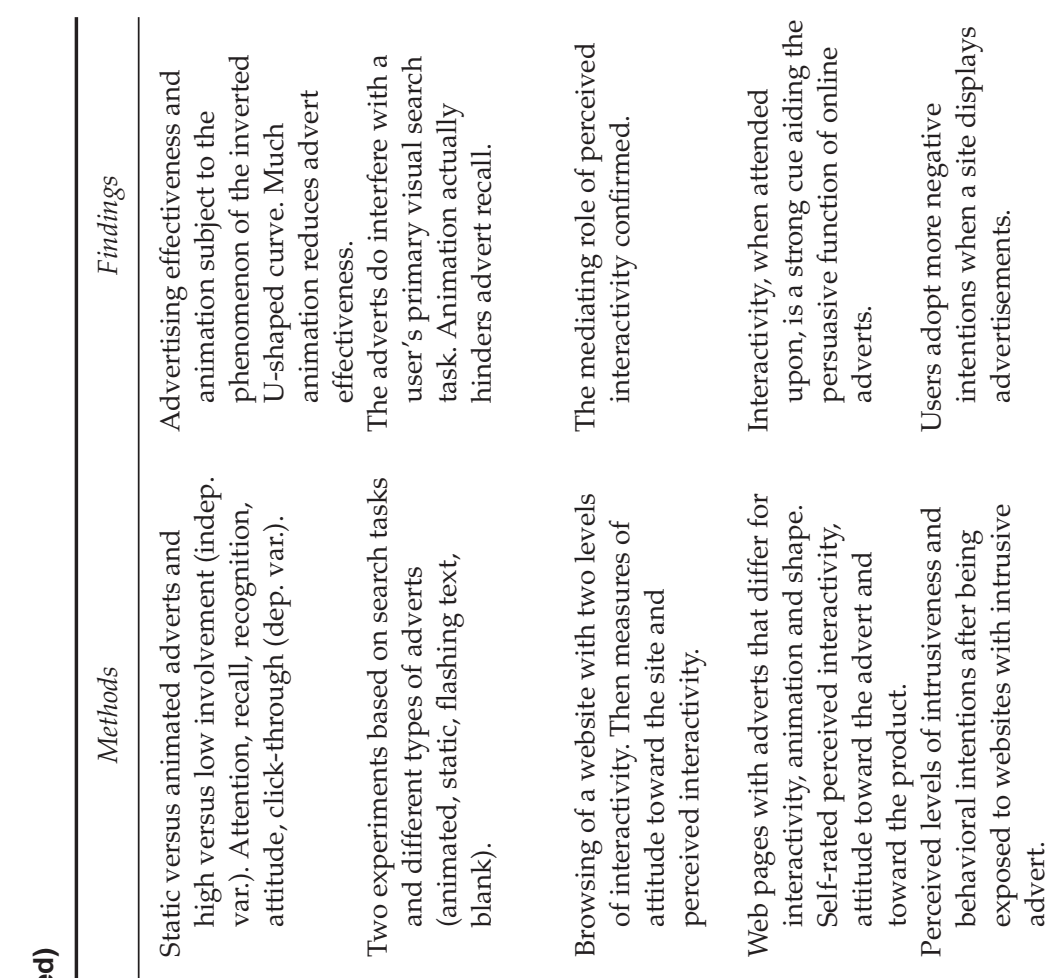

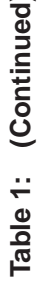

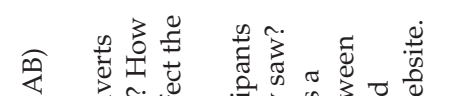

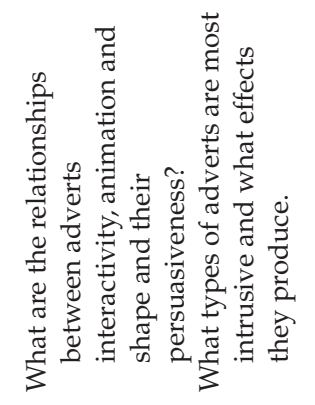

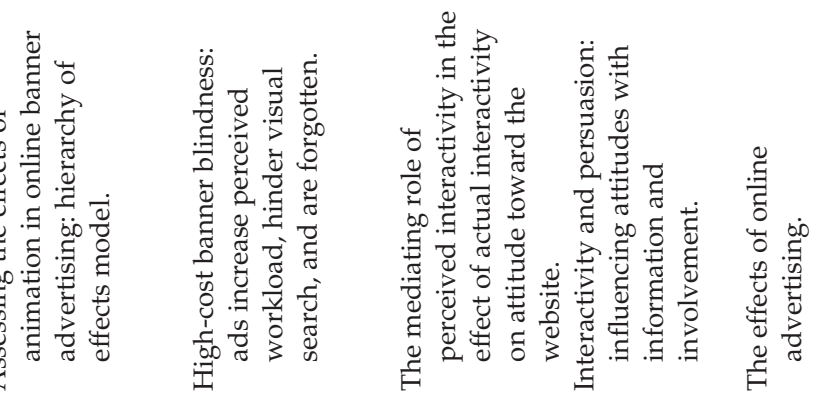

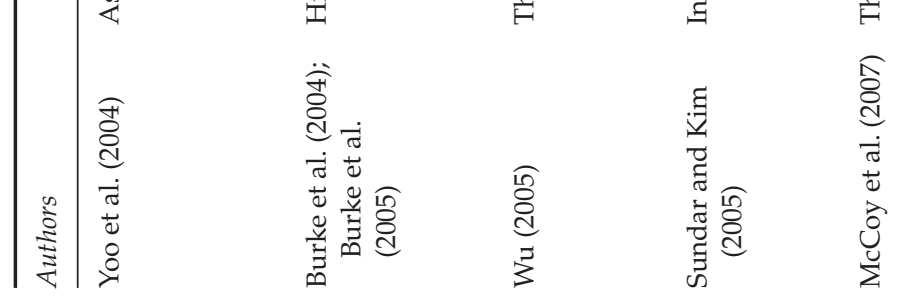




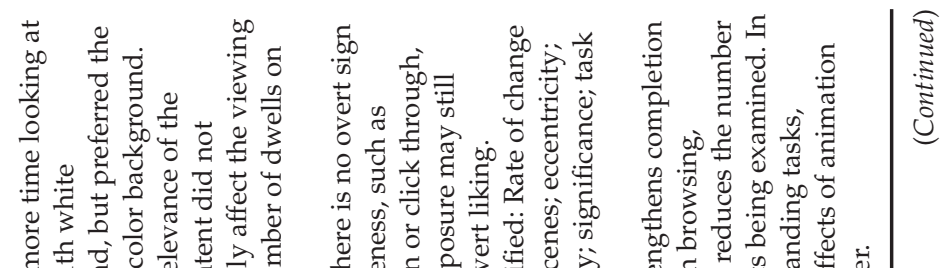

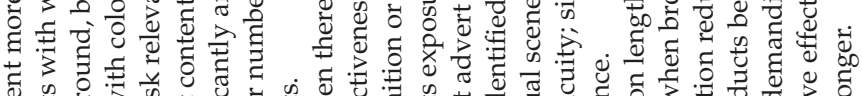

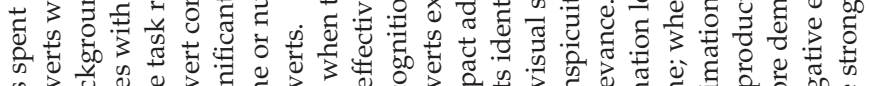

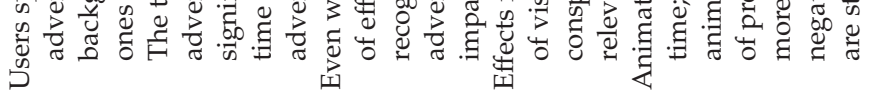
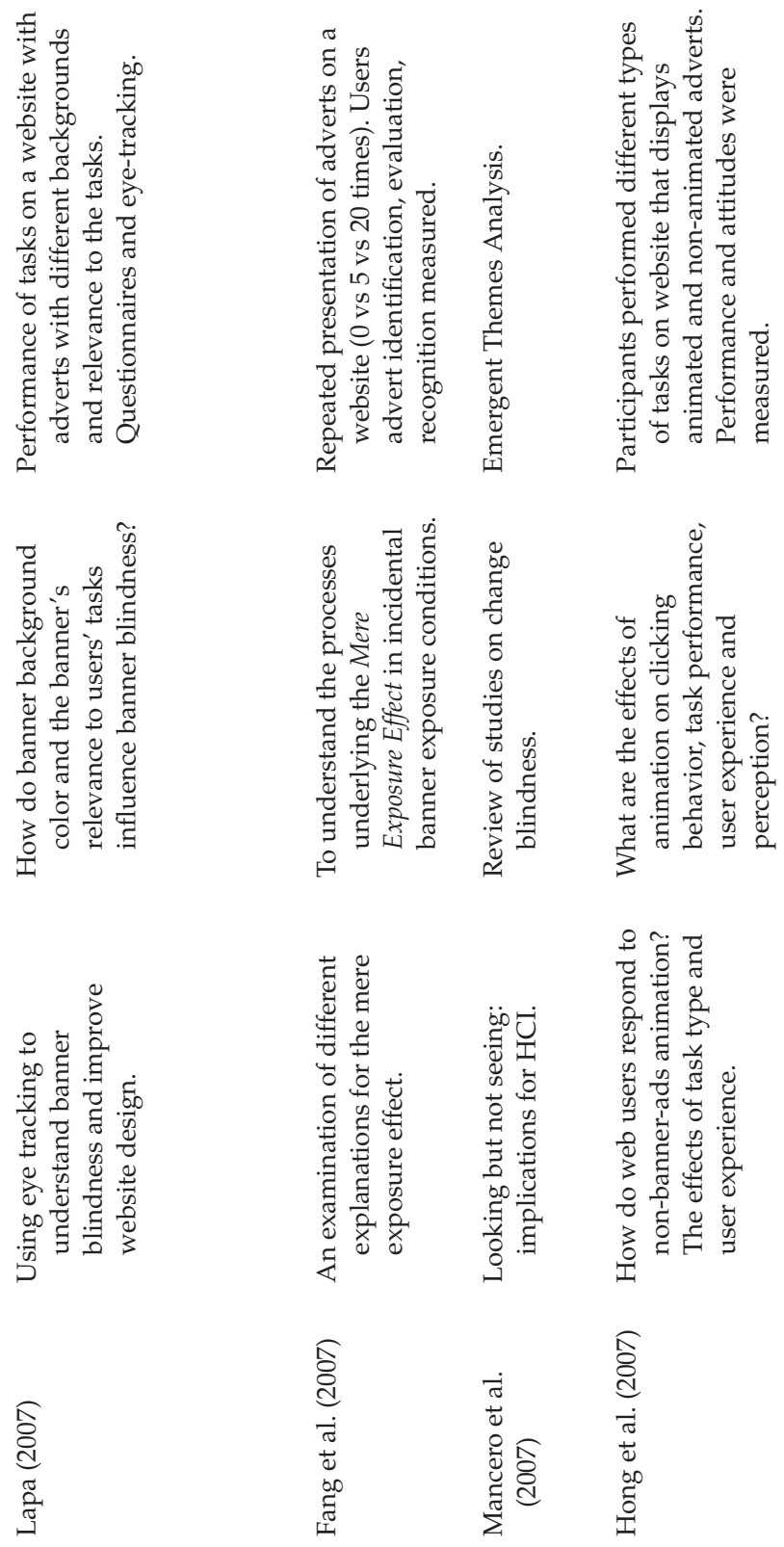


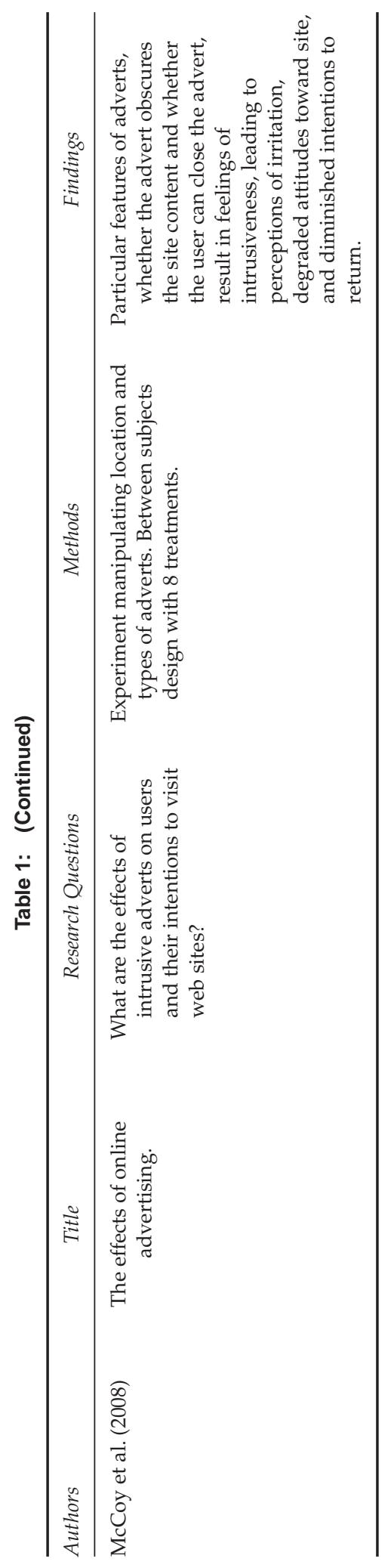


Table 2: Summary of Effects of Advertising Features

\begin{tabular}{|c|c|}
\hline Feature & Effects \\
\hline Animation & $\begin{array}{l}\text { - reduces banner blindness (Bayles, 2000) } \\
\text { - does not affect advert recognition (Bayles, 2002) } \\
\text { - does not affect advert recall and recognition (Drèze \& Hussherr, 2003) } \\
\text { - increases recall and positive attitudes toward the advert, is moderated by } \\
\text { involvement, has inverted U-shape (Yoo et al., 2004) } \\
\text { - animation speed is important (Sundar \& Kalyanaraman, 2004) } \\
\text { - improves attitude toward adverts; worsens attitude toward product } \\
\text { (Sundar \& Kim, 2005) } \\
\text { - slows visual scan, worsen recall (Burke et al., 2004; Burke et al., 2005) } \\
\text { - increases clicking behavior, lengthens time, reduces focused attention, } \\
\text { fewer items are examined, affects more browsing than searching (Hong } \\
\text { et al., 2007) }\end{array}$ \\
\hline Interactivity & $\begin{array}{l}\text { - improves perception, attitude, persuasion and comprehension (Macias, } \\
\text { - is mediated by perceived interactivity with respect to attitude (Wu, 2005) } \\
\text { - improves persuasiveness and covers animation (Sundar \& Kim, 2005) }\end{array}$ \\
\hline Relevance & $\begin{array}{l}\text { - non relevant adverts increase distraction and consume attention (Cho, } \\
\text { 1999) } \\
\text { - increases clicking intentions (Cho, 1999), especially for users that have a } \\
\text { positive attitude toward the website; relevant adverts lead to more } \\
\text { positive attitude toward the advert ; users follow the direct, high } \\
\text { involvement route } \\
\text { - increases reactance and reduces intrusiveness (Edwards et al., 2002) } \\
\text { - combined with pop-ups/pop-unders increases feeling of intrusiveness } \\
\text { and reduces recall of web content (McCoy et al., 2007) } \\
\text { - does not affect dwell time (Lapa, 2007) }\end{array}$ \\
\hline Repetition & $\begin{array}{l}\text { - increases recall and recognition (Drèze \& Hussherr, 2003) } \\
\text { - increases fluency, improves affect and cognition; it improves recognition } \\
\text { (Fang et al., 2007) }\end{array}$ \\
\hline Form & $\begin{array}{l}\text { - Shape of the advert does not matter as much as content of the advertising } \\
\text { (Drèze \& Hussherr, 2003; Lapa, 2007) }\end{array}$ \\
\hline Intrusiveness & $\begin{array}{l}\text { - Users are irritated by intrusive adverts (Edwards et al., 2002) } \\
\text { - Intrusive adverts degrade attitude toward site and diminish intentions to } \\
\text { return (McCoy et al., 2008) }\end{array}$ \\
\hline Novelty/ Familiarity & $\begin{array}{l}\text { - Users pay attention to adverts at the beginning; after they learn the page } \\
\text { layout, dwell time decreases (Lapa, 2007) } \\
\text { - User experience with animated adverts reduces effects of animation } \\
\text { (Hong et al., 2007) }\end{array}$ \\
\hline Miscellaneous & $\begin{array}{l}\text { - Banner blindness does not affect only banners (Benway \& Lane, 1998); it } \\
\text { affects most peripheral changes, highlighted items, non relevant items } \\
\text { (Mancero et al., 2007) } \\
\text { - High product involvement increases intentions to click (Cho, 1999) } \\
\text { - A positive attitude toward the website leads to more positive attitude } \\
\text { toward the advert (Cho, 1999) } \\
\text { - Directed browsing leads to lower advert recall and recognition } \\
\text { (Pagendarm \& Schaumburg, 2001) } \\
\text { - Users avoid looking at adverts; this does not depend on experience in } \\
\text { using the Internet (Drèze \& Hussherr, 2003) }\end{array}$ \\
\hline
\end{tabular}


Li and Leckenby (2004) discussed the "hierarchy of effects" model, which encompasses cognition, affection, and behavior $(\mathrm{CAB})^{5}$ and illustrate how advert effectiveness may be framed as a combination of these three criteria, and indeed how different orderings of these criteria achieve different results. For example, the "learning hierarchy" C-A-B occurs when a consumer first learns/interprets the message conveyed by the advert (learn), then certain emotional changes take place (feel), and finally a certain behavioral intention occurs (do). Other sequences are possible, like the "dissonance hierarchy" B-A-C, where somebody first acts toward the product, then feels something about it, and finally learns its benefits, or the "low-involvement hierarchy" B-C-A, where a free sample of the product is first used, then some of its properties are learned, and finally a positive feeling is eventually derived.

The CAB model can also be applied when evaluating the quality of user experience with a generic website, extending in such a way the range of factors addressed by typical usability studies. In this context, cognition refers to comprehension, recognition, and recall of the web pages content (e.g., news articles), affection refers to attitude toward the website, aesthetic judgments, arousal levels, positive or negative feelings, whereas behavioral intentions include the intentions to visit the website again, to keep visiting other pages, to read top-to-end an article, to refer a page to friends, and so on. Future studies should investigate if different orderings of the $\mathrm{CAB}$ components make a difference for the user interaction with websites, as they do for adverts.

Banner blindness is closely related to the inattentional and change blindness phenomena, all suggesting that under certain circumstances even salient characteristics of adverts fail to grab users' attention (Bayles, 2000; Benway \& Lane, 1998; Burke, Gorman, Nilsen, \& Gorman, 2004; Burke, Hornof, Nilsen, \& Gorman, 2005; Mancero, Wong, \& Amaldi, 2007; Pagendarm \& Schaumburg, 2001). Change blindness (Simons \& Levin, 1997) is the difficulty people face when detecting changes to visual stimuli that occur across views, sometimes even when the changing object is being attended to. Inattentional Blindness (Mack \& Rock, 1998) is a related phenomenon that occurs when observers fail to notice the presence of unattended stimuli, even when these stimuli are presented within an observer's eld of view and occupy the same location as attended and consciously perceived stimuli. Both these kinds of phenomena need to be taken into account by web designers, for example, any time they decide how to render certain changes at the level of the user interface, that should be noticed by users without delays.

Other relevant phenomena are brought into account by the Central/Limited Capacity Theory and the Perceptual Bandwidth Theory concerning attention (Hong, Thong, \& Tam, 2007; Lang, 2000; Macias, 2003; Reeves \& Nass, 2000; Sundar \& Kim, 2005). The Limited Capacity Theory assumes that people are information processors with limited capacity and that attention is affected by factors that are intentional, like user's goals, and unintentional, like novelty, change, and intensity of the stimuli. The Perceptual Bandwidth Theory, on the other hand, posits

\footnotetext{
${ }^{5}$ Cognition refers to the knowledge in a person's mind and how that is obtained, affection is related to both emotional and attitudinal aspects of meaning (e.g., liking and disliking), and behavior refers to observable acts on the part of persons or their stated intentions to act (behavioral intentions).
} 
that psychologically significant aspects of the user interface may result in sensations which compete for the same finite amount of available mental effort needed to comprehend and memorize information. A main consequence is that the experience of viewing a flashy advert may be memorable, but this may come at the cost of actual memory for product information contained in the advert (Sundar \& Kim, 2005). By analogy, similar effects could be expected when users attend at certain prominent elements of the user interface (unintentional factors), and process them at the cost of not processing (by reading, understanding, remembering) other contents that might be more relevant to accomplish for the task at hand.

An interesting point suggested by the Modified Elaboration Likelihood Model (Cho, 1999; Petty \& Cacioppo, 1983, 1986) is that there are two routes to user persuasion. Persons that have high involvement with a product/brand or high motivation, ability, opportunity to process communication, are more likely to exert a high cognitive effort (i.e., elaboration likelihood) when perceiving the advert. On the other hand, when involvement, motivation, ability, or opportunity is low, people are not willing or able to exert processing effort, and peripheral cues (visual attractiveness, music, animation, humor) become determining factors. If we apply this model to user interaction with websites, we could argue that for people involved in directed/semidirected browsing, hence more concentrated on the task, persuasion could be achieved by following both routes, whereas for people involved in undirected browsing, only the second route can be exploited: the importance of being provided with appropriate peripheral cues (e.g., attractiveness, animation, music, speech, human images, humor) is key. Sophisticated models of eye movement and visual encoding (Salvucci, 2001) and studies predicting visual scan patterns (Buscher, Cutrell, \& Morris, 2009) can help deciding which visual cues to use and how to implement them.

If matching adverts content/topic with the anticipated audience preferences and motivational needs might be a good strategy to reach persuasion goals, it should be noted that website users are often very diversified in terms of personal attributes and preferences (e.g., age, gender, abilities, cultural backgrounds), which makes it more difficult for an advertising message to affect them all in the same way. However, advert designers might recur to a judicious use of typical attention directing effects of media, such as speech and human images, that have been found to produce strong effects on users, such as context switching: from receiving information and acting in the world to conversational interaction with another person (Reeves \& Nass, 1996; Computer As Social Actors paradigm). As a consequence of this context switch, web users engaged in a search task might revert from a plan-act-interpret cycle (typical of task related behavior, which is less affected by external distractions) to the interpret-plan-react mode (typical of human conversation, which might facilitate persuasion effects by adverts).

Because it is common that adverts are exposed for relatively short times while the user is attending at other things (Fang, Singh, \& Ahluwalia, 2007), the Mere Exposure Effect applies; it posits that people develop a positive attitude to unknown stimuli just because they have been repeatedly and briefly exposed to them. This would suggest interesting strategies to apply and further test on websites to drive attention or foster learning regarding new features (e.g., by showing tooltips), based on repeating the presentation of the novel items at time intervals to increase 
the chances of a positive response to them by users. However, we should also expect a decrease in performance, according to Burke et al. (2005).

Finally, two additional theoretical concepts are considered, the Need for Cognition and the Need for Emotions: The former "refers to an individual's tendency to engage in and enjoy effortful cognitive endeavors . . . and this characteristic is predictive of the manner in which people deal with tasks and social information"; the latter is defined "as the tendency or propensity for individuals to seek out emotional situations, enjoy emotional stimuli, and exhibit a preference to use emotion in interacting with the world" (Macias, 2003). If we reframe these concepts in the context of user interaction with websites, users with high need for cognition would be affected by stimulating, reliable, and relevant contents, whereas users with high need for emotions might be more affected by the way contents are presented on the website (e.g., novel interactive features that engage the user in gamelike activities).

\subsection{How Do Adverts Affect Website Usability?}

These effects include all the usability factors: User effectiveness, efficiency, and satisfaction may be affected by adverts and can be measured by typical usability metrics like success rate and level, error rate, time on task, perceived level of effectiveness, productivity and effort, cognitive load, and so on (Rubin \& Chisnell, 2008). Other variables that are typically used include results from reading and comprehension tasks, memory recall of the website contents, and ease of distraction from original goal. Finally, other possible dependent variables are related with affective aspects, like hedonic ones (stimulation, identification), judgments of beauty or goodness (Hassenzahl, 2001, 2004), or with perception of usability (of one's own effectiveness or efficiency), which may be precursors of changes in user attitude with respect to the website, its brand, and its contents.

By viewing banner blindness as a special case of inattentional and change blindness, we can understand why so often salient characteristics of adverts are not only unable to grab users' attention but on the contrary produce a deterioration of user performance in navigating a website or carrying out more specific tasks. The Limited Capacity Theory and the Theory of Perceptual Bandwidth explain why adverts "consume" attention resources, to which people adapt by developing specific viewing strategies leading to blindness that can affect no only adverts but also other website components (content and interaction components). This can increase the negative effect of the feedback loop shown in Figure 1. Introducing adverts whose content is relevant with respect to website topics or users tasks has been suggested as a way of increasing advert awareness and reducing banner blindness. However, this effect has not proved to easily turn into stable gains in term of advert recall or improved usability of a website. Consumers' exposure to repeated adverts presentation has shown to be a better solution to banner blindness. This is compliant with the Mere Exposure Effect (Fang et al., 2007), which improves adverts awareness and contributes to the development of a positive attitude toward the adverts in question. Especially for undirected or semi-directed 
browsing, relevant adverts and repeated exposures could indeed reduce negative affection while having a limited negative impact on usability (Burke et al., 2005), by providing additional sources of interests, by satisfying unexpected needs, and by supporting the expected value of adverts. In other words, adverts could be the means to support users, as hypothesized by the Need for Emotions theory (Macias, 2003). In this way, adverts could even reduce the negative effects of the feedback loop.

If we consider web user interaction solely in terms of cognition (attention, knowledge, and memory for website contents), adverts in general have the effect of slowing down information search, of increasing perceived workload (Burke et al., 2004; Burke et al., 2005), and of interfering with website content retention (McCoy, Everard, Polak, \& Galletta, 2007). This is especially true if adverts are popups and pop-unders. Further evidence has suggested that when users' cognitive resources are focused on performing goal-directed tasks, interruptions or distractions caused by adverts are perceived as more severe (Edwards, Li, \& Lee, 2002) and low levels of advertising awareness are expected (Drèze \& Hussherr, 2003). This is consistent with theories of attention showing that information "encoding" requires attention, and interruption interferes with attention and memory (Naveh-Benjamin, Guez, \& Marom, 2003).

To decide whether it is appropriate to interrupt a user thinking process, approaches based on estimating the cost of interruptions (Horwitz, Apachible \& Koch 2004) could be conceived: They are based on estimating the "state of interruptability" of a computer user from a stream of desktop events and a model (previously trained on the basis of user judgments of how much they would be willing to pay not to be interrupted in given circumstances). However, for adverts delivered on the web this approach is not viable because (a) no stream of such desktop events is available, and (b) probably for the vast majority of users, their willingness to pay in order to exclude adverts would be high.

For users under these conditions, sense-making becomes more complex, and more demanding from a cognitive and emotional point of view. Rather than leading to the flow state (with its benefits), interaction becomes a situation where the feedback loop described in Figure 1 is likely to ensue, leading to more and more negative affective states.

The feedback loop may establish also when adverts intrusiveness generates negative feelings such as irritation (Edwards et al., 2002), negative attitudes toward the website (McCoy et al., 2007), and wearout. In turn, this brings consequences such as development of more negative attitudes, fewer, and shorter visits to the website, fewer positive referral acts, more negative word-of-mouth intentions. Thus intrusiveness may impair the ability of a website to obtain user trust.

\subsection{How Do Adverts Affect Consumer Responses?}

Consumer responses are effects related to changes in users' cognition, attitude, and emotions with respect to the messages conveyed by the advertising (and therefore with respect to products and brands mentioned by the advert); they include the 
ability to recognize and recall the advert, the brand and the product, arousal, ${ }^{6}$ perceptual fluency, ${ }^{7}$ wearout, ${ }^{8}$ and reactance. ${ }^{9}$ Outcomes of an advert include also activities and decisions like ignoring it; forgetting it; attending to it; forming or changing an attitude toward the advert, toward the brand, or toward the product mentioned by the advert; e-mailing the advertiser; searching information about the product; referring the advert, brand, or product to others; and purchasing the product.

Relevant metrics include recall and recognition rates of adverts, products, and brands; changes in attitudes and in affective state; behavioral intentions; impressions; rollover counts; dwell time on adverts ${ }^{10}$; click-through rates; acquisition and conversion rates; and recurrence of advertising views. ${ }^{11}$ Some of these metrics can be measured from data gathered by web servers and advert servers logs, others from appropriate page-tagging mechanisms, and others only through investigations with real users (e.g., interviews, questionnaires, surveys, focus groups, user testing).

Many studies have tried to empirically test the intuition, widely held by advertisers, that animated adverts are better able to grab consumers' attention and are easier to remember if compared to static ones. Although the former assumption has been confirmed by Yoo, Kim, and Stout (2004), evidence regarding the latter is more contradictory in terms of advert recall and recognition results (Bayles, 2000, 2002; Burke et al., 2004; Burke et al., 2005). A possible explanation is that the animation effect is subject to the phenomenon of the inverted U-shaped curve (Yoo et al., 2004): Too much animation may reduce the advertising effectiveness due to the consumer's limited cognitive capacities or negative affective responses toward the advert (e.g., annoyance, irritation). Animation is effective in grabbing attention and reducing banner blindness but, as predicted by the Limited Capacity Theory, it lengthens time, reduces attention, and worsens attitude toward products. Animation can also interfere with the knowledge acquired on advertised products. Pagendarm and Schaumburg (2001) found that both in directed and undirected browsing, the perception period for the adverts might be too short for a deeper processing of animated advertising texts. This is further supported by the findings of Sundar and Kalyanaraman (2004), who suggested that advertisers

\footnotetext{
${ }^{6}$ Arousal is a state of heightened physiological activation, which can be measured by recording skin conductance level.

${ }^{7}$ Perceptual fluency refers to the ease with which information/stimuli can be perceived or processed by a person.

${ }^{8}$ Wearout is a negative effect due to consumer satiation or tedium. Wearout can be manifested by lack of attendance or click-through on adverts. In traditional media a two-factor theory provides strong support for an inverted-U relationship between the number of advert exposures and responses. This relationship is caused by two opposing factors. In the initial wear-in stage, increased response opportunity with each additional advert exposure leads to an increase in affect. Subsequently, satiation (or tedium) leads to wearout, when each additional exposure has a significant negative effect.

${ }^{9}$ Clee and Wicklund (1980) described reactance as a boomerang effect in which the perception of coercion is met with an equal but opposite influence, which is used by consumers to restore their freedom of choice; for example, when radio listeners are enjoying music, the threat of advertising may result in channel surfing to regain the freedom to listen to music.

${ }^{10} \mathrm{An}$ advert dwell time is the elapsed time between the entry and exit of the participant's gaze on the advert area.

${ }^{11}$ Recurrence is the number of times the participant's gaze returns to the advert.
} 
wanting to generate positive impressions and high recall of their products should adopt fast-to-slow animation sequences to better achieve their goal.

Interactivity, especially when it is perceived as such, improves persuasion, attitudes, and comprehension, in agreement with the Modified Elaboration Likelihood Model (Cho, 1999). Interactive adverts have been found particularly suited to favor advert comprehension, branding (Macias, 2003), and persuasion (Sundar \& Kim, 2005). They have also proved to increase positive attitudes and feelings (Gao, Rau, \& Salvendy, 2009; Macias, 2003).

Positive feelings can also be enhanced by repeated adverts exposures. Fang et al. (2007) found a significant linear trend in positive evaluations of adverts as exposure frequency increased, suggesting that even when there is no overt sign of effectiveness, such as recognition or click-through, repeatedly exposed adverts may still impact advert liking. They also observed a relatively high level of tolerance for repeated exposure to banner adverts by consumers (with no wearout effect even after 20 exposures); this finding could encourage web advertisers to further explore adverts repetition as a strategy to raise adverts and brand awareness (see also Drèze \& Hussherr, 2003).

Regarding user behavior, click-through rates have been often used as measures of adverts success or failure in affecting consumer responses. Most researchers have generally found click-through levels to be quite low, specifically when users focus on goal-directed tasks, and the situation does not change even in the case of repeated exposures to adverts (Drèze \& Hussherr, 2003). However, in recent years, several scholars pointed out that the click-through rate might not be such a good measure of advert performance (Drèze \& Hussherr, 2003; Fang et al., 2007). The click-stream model described by Patrali, Hoffman, and Novak (2003) suggests that advert exposures that do not immediately lead to a click may still lead to enduring outcomes. For instance, advert exposures in prior interactions with a website could raise the click probability in future visits to the same or a different website.

Other measures of user behavior, derived from eye-tracking data, offer a valuable supplement to click-through rates or consumers' responses to questionnaires. The observation of dwell time on adverts in (Lapa, 2007) provides a deeper look into participants behaviors, showing that users spend more time on adverts during surfing, compared to goal-driven browsing. Also, contrary to expectations, the adverts on which users spend more dwell time might not correspond to the ones they prefer, as indicated by their answers to a questionnaire.

\subsection{Main Limitations of the Studies Considered}

It is important to consider a number of possible confounding factors that may affect the experimental results reported in this review. In particular, we believe it is important to conduct experimental investigations by employing real, instead of ad-hoc created, websites. This should increase the ecological validity of the collected results and provide a more reliable picture of the user experience with online advertising. Similarly, the type of adverts selected in this kinds of experiments should be chosen among the most commonly used ones in the Internet, 
instead of developing artificial ones that might fit the specific purposes of a certain study, but lead to poor validity of the study.

Researchers and practitioners should also extend the range of web user categories involved in their experiments, because current results are mainly based on university students (Gao et al., 2009; Macias, 2003). Although young adults with higher education levels are an important segment for advertising, there are many other segments that so far have not been extensively studied in terms of usability effects and advert response, which may turn out different because of several factors, including age, prior exposure and attitude toward technologies, generic preferences, and so on.

\section{RESEARCH AGENDA}

Although the studies we reviewed present many findings and theories, we believe other research avenues need to be explored before an optimal choice and allocation of adverts on web pages can be reliably made.

\subsection{Effects on Usability and on the User Experience}

One such avenue deals with effects of online display adverts on usability and quality of the user experience. We know that placement of online advertising can bring many benefits, such as increased chances of repeated visits to the website by users, more purchases, interest and comprehension of web contents, and reduced risk of abandonment. But wherever the feedback loop in Figure 1 ensues, users will have fewer chances to look at advertising and to elaborate it, they will be increasingly entangled into tunnel vision, they will slow down, they will struggle to accomplish what they wanted to, and they will inevitably develop a more negative attitude toward the website. To what extent does online display advertising affect these usability or affective variables? How do these effects depend on the "density" of adverts? And on different types of adverts-for example, text adverts, static small images, animated images, intrusive ones? Is there interaction between these factors and web page content or self-promotional material? Is there any possible compromise between negative consequences of adverts and their consumer-related benefits? So far only a limited set of metrics and phenomena have been studied, namely banner blindness, irritation, perceived workload, time-on-task, negative attitudes. No study focused on important usability-related metric like effectiveness (e.g., success level, success rate, user errors, accuracy, and completeness of gathered information, performance in reading tasks).

\subsection{Enhanced User Experience Evaluation Framework}

Websites tend to be increasingly emotional artifacts, aimed at producing certain experiences on their users. A global user experience evaluation framework could be developed, based on theories and findings discovered in studies focused 
on advertising. Theories and hypotheses like the Hierarchy of Effects (CAB), the Limited Capacity Theory, the Perceptual Bandwidth Theory, the Elaboration Likelihood Model, and the Mere Exposure Effect theory could all be applied to web content different than advertising. The outcome of such an effort would extend the range of variables that are used when characterizing the user experience, could provide interesting insights on observed phenomena, and could help making informed design decisions. For example, it would be interesting to know what the effects of changing the order of web contents would be when pages try to achieve their persuasive goals in terms of (a) affect (i.e., creating user curiosity, desire), (b) cognition (i.e., explaining things), and (c) behavior (i.e., providing explicit suggestions). How would these effects change if the order would be a more conventional C-A-B? or a B-C-A?

\subsection{Integration of Models for Advertising and for User Interfaces in Divided Attention}

Another direction to pursue is the integration of models studied in the marketing/advertising area and those related to notification and attentive user interfaces to address design issues concerned with interruption and intrusiveness in divided attention situations. With more encompassing models, better decisions could be made by web designers and adverts creators when designing and deploying adverts on web pages.

A notification system "attempts to deliver current and important information to users in an efficient and effective manner without causing unwanted distractions to ongoing tasks"; attention-centric systems "can adapt information delivery to avoid overloading the user" (Bailey, Konstan \& Carlis, 2001; McCrickard, Catrambone, Chewar, \& Stasko, 2003a; McCrickard \& Chewar, 2003b; McCrickard, Czerwinksi, \& Bartram, 2003c). These studies focus, for example, on visual encoding strategies deploying animated icons, different colors, and different distances from the locus of attention to reduce the impact on the primary task execution; or they focus on the effects that interruption lags may have on how easily an interrupted task can be later resumed, or on models of cost of interruptions; or on evaluation frameworks based on user benefits characterized along dimensions like interruption (the benefit due to reallocating attention between tasks), comprehension (the benefit due to understanding the notified message), and reaction (the benefit due to user's ability to make decisions and to respond to the notification).

We believe that a website also delivering adverts could be seen as a type of notification system, where the notified message is the advert. Although all these models should in general apply, it is not clear how well do they cover the specifics of notifying adverts; for example, the benefits are definitely not the same: Satisfaction has to be added, as well as emotions and relevance.

The approach based on cost (Horvitz, Apachible \& Koch, 2004) could be pursued to model the trade-off that users make when tolerating more or less intrusive adverts. How dynamic are those trade-offs? How much do they change depending on the kind of primary task being carried out? How much do they depend on user characteristics? 
Because the content of an advert is richer than an event notification, could theories like Hierarchy of Effects, Limited Capacity, Perceptual Bandwidth, Elaboration Likelihood Model, Mere Exposure Effect, persuasive psychological effects be integrated with attention-centric user interface principles and yield interesting insights? For example, to further extend the benefit framework, or the interruption cost model. Or to further study which visual encoding strategies could lead to quicker or stronger persuasion, and under which circumstances.

\subsection{Interactions Between Adverts}

More precise hypotheses on the effects of interactivity, repeated exposure, and intrusiveness should be further tested by minimizing any interference caused by confounding factors and by addressing issues related to interaction between the different factors, as in the case of the contextual presence of different types of adverts on a same page. What happens when a page contains multiple instances of interactive, animated, and rich media adverts is currently not clear. It is possible that negative effects induced by some of these adverts spill over to other adverts and to the hosting website.

\subsection{Generalizing Tasks}

Effects of user learning on adverts response (e.g., user experience with animated adverts reduces effects of animation, as pointed out by Hong et al., 2007) and the specific characteristics of the tasks performed by users need to be studied more extensively, possibly generalizing task models beyond shopping ones and the distinction between directed, semidirected, and undirected browsing. For instance, by taking into account social network sites it would be possible to analyze the user experience with adverts while performing more articulated and longitudinal types of tasks (e.g., the creation and sharing of contents with friends).

\subsection{Persuasiveness of Adverts Within Web Sites}

Given that the purpose of most website is to persuade visitors to act or think in a certain way, all the theories and findings mentioned above are relevant to a website's success. If important cues or information or interaction widgets are implemented in such a way that they are subject to blindness, they will not be attended upon. If users' attention is very focused, according to the Limited Capacity Theory, they will pay little intentional attention to seemingly irrelevant page components, even if they may be important for reaching their goals. Persuasiveness depends on the elaboration likelihood, and page components should be designed in such a way that either of the two persuasion routes could be followed. User experience with the page layout has to be taken into account by designers to optimize the rendering of important page components, as well as context-related judgments of the design qualities of a website. To our 
knowledge, more studies are needed to fully understand how psychological factors deployed by persuasive technologies (Reeves \& Nass, 1996; Fogg, 2003), such as the halo, reciprocity, and affinity effects, could turn out to be effective in adverts within websites. New advert formats, deploying dynamic media including video and speech, humorous devices, and several response options (Gao et al., 2009) might have strong attention directing effects and the capacity of engaging users in more conversational reaction mode. Discovering how to extend the Modified Elaboration Likelihood Model by encompassing also these effects and applying it to websites delivering adverts is also a research direction worth pursuing.

\section{CONCLUSIONS}

This review covered several psychological theories, outlined a number of research questions, and highlighted the main results that have been experimentally validated concerning effects of display advertising.

We saw that usability consequences of adverts can be ascribed to problems with user attention: stealing it from task execution and not attending to adverts and other components of the user interface; some of these problems are more severe when tasks are more demanding. Other quality risks can be ascribed to intrusiveness of adverts and lack of control by users; also in this case, severity depends on task type.

Considering effects of adverts with respect to the message or brand that they convey, animation is controversial as a feature: Up to a certain point it appears to be effective, but beyond a saturation level it is detrimental not only with respect to the hosting website but also with respect to advert content. Intrusiveness has also negative consequences. On the other hand, interactivity of the advert or its repeated exposure appear to be effective. Relevance of the advert content with respect to the user goal or page content has not been proved to be effective; a better solution appears repeated exposures.

Stakeholders involved with websites where advertising is being displayed should be aware of these results to inform trade-off judgments when designing web pages, adverts, and allocating them to pages.

There are many variables related to effectiveness of advertising that could be applied to other page components: ability to notice page components, attention and arousal levels, attitudes toward the website, likelihood to elaborate page components, ability to recall page components and to recognize them, intentions to return to the website and to refer it to friends, irritation due to inability to complete a task, and the ensuing of flow state. We believe that all these constructs should be used when assessing quality of a website, in addition to more traditional usability metrics, centered on effectiveness, efficiency, and satisfaction. Focusing quality assessments on all these constructs provides evaluators with a wider range of factors, increasing their ability to monitor quality and detect quality risks that can hinder cognitive and emotional effects of browsing.

Some particular adverts features may be important to consider, too-for example, interactivity. We saw that interactive adverts improve perception, attitude, 
comprehension, and persuasion. We suspect that this can be true for other webpage components, not just adverts: Properly designed interactive features (i.e., attractive and usable ones) might improve the user experience. One reason why web applications like Facebook are so successful may indeed be because of their level of interactivity, making their use slightly more challenging, novel, and varied over time. Interactivity may also be key to facilitate the ensuing of the flow state in more engaging interfaces (like games), with its expected benefits.

Regarding online newspapers websites, effective adverts are key to their survival and success, but designers should be careful not to jeopardize usability or the other positive effects that are expected. Well-designed and placed adverts can even improve the chances for end users to engage with emotionally attractive and rewarding information.

We believe that by starting from available results on adverts effects, the enormous impact and momentum that Internet advertisement has, and the corresponding variety of adopted solutions, further research in this field is possible and welcome. This could contribute to validate current knowledge and better support all stakeholders involved in the creation, placement, evaluation, and publication of ecologically sustainable online advertising.

\section{REFERENCES}

Bailey, B. P., Konstan J. A., \& Carlis, J. V. (2001). The effects of interruptions on task performance, annoyance, and anxiety in the user interface. In M. Hirose (Ed.), Proceedings of 2001 Human-Computer Interaction- INTERACT 2001 Conference (pp. 593-601). Amsterdam: IOS Press.

Bayles, M. J. (2000). Just how blind are we to advertising banners on the web. Usability News, 2(2), 520-541. http://www.surl.org/usabilitynews/22/banners.asp

Bayles, M. J. (2002). Designing online banner advertisements: Should we animate? In CHI '02: Proceedings of the SIGCHI Conference on Human Factors in Computing Systems (pp. 363-366). New York: ACM.

Benway, J. P., \& Lane, D. M. (1998, December). Banner blindness: Web searchers often miss "obvious" links. In Internetworking (Vol. 1.3, ITG Newsletter). http:/ / www.internettg.org/newsletter/dec98/banner_blindness.html

Burke, M., Gorman, N., Nilsen, E., \& Hornof, A. (2004). Banner ads hinder visual search and are forgotten. In CHI '04 Extended Abstracts on Human Factors in Computing Systems (pp. 1139-1142). New York: ACM.

Burke, M., Hornof, A., Nilsen, E., \& Gorman, N. (2005). High-cost banner blindness: Ads increase perceived workload, hinder visual search, and are forgotten. ACM Trans. Computer-Human Interaction, 12, 423-445. http:/ / doi.acm.org/10.1145/1121112.1121116

Buscher, G., Cutrell, E., \& Morris, M. R. (2009). What do you see when you're surfing? Using eye tracking to predict salient regions of web pages. CHI '09, 21-30.

Cho, C. H. (1999). How advertising works on the WWW: Modified Elaboration Likelihood Model. Unpublished technical report, University of Texas at Austin. http://www. ciadvertising.org/studies/reports/info_process/jcira.html

Clee, M. A., \& Wicklund, R. A. (1980). Consumer behavior and psychological reactance. Journal of Consumer Research, 6, 389.

Csikszentmihalyi, M. (1990). Flow: The Psychology of Optimal Experience. New York: Harper and Row. 
Drèze, X., \& Hussherr, F. X. (2003). Internet advertising: Is anybody watching? Journal of Interactive Marketing, 17(4), 8-23.

Edwards, S. M., Li, H., \& Lee, J. H. (2002). Forced exposure and psychological reactance: antecedents and consequences of the perceived intrusiveness of pop-up ads. Journal of Advertising, 31(3).

Fang, X., Singh, S., \& Ahluwalia, R. (2007). An examination of different explanations for the mere exposure effect. Journal of Consumer Research, 34, 97-103.

Fogg, B. J. (2003). Persuasive Technology. New York: Morgan Kaufmann.

Gao, Q., Rau, P. P., \& Salvendy G. (2009). Perception of interactivity: Affects of four key variables in mobile advertising. International Journal of Human-Computer Interaction, 25, 479-505.

Gibbs, W. (2008). Examining users on news provider web sites: A review of methodogy. Journal of Usability Studies, 3, 129-148.

Hartmann, J., Sutcliffe, A., \& De Angeli, A. (2008). Towards a theory of user judgment of aesthetics and user interface quality. ACM Transactions on Computer-Human Interaction, 15(4), 1-30.

Hassenzahl, M. (2001). The effect of perceived hedonic quality on product appealingness. International Journal of Human-Computer Interaction, 13, 481-499.

Hassenzahl, M. (2003). The thing and I: Understanding the relationship between user and product. In M. Blythe, K. Overbeeke, A. F. Monk, \& P. C. Wright (Eds.), Funology. Amsterdam: Kluwer Academic, 31-42.

Hassenzahl, M. (2004). The interplay of beauty, goodness, and usability in interactive products. Human Computer Interaction, 19, 319-349.

Hassenzahl, M. (2006). Hedonic, emotional, and experiential perspectives on product quality. In C. Ghaoui (Ed.), Encyclopedia of human-computer interaction (pp. 266-272). Hershey, PA: Idea Group Publishing.

Hassenzahl, M., Schöbel, M., \& Trautmann, T. (2008). How motivational orientation influences the evaluation and choice of hedonic and pragmatic interactive products: The role of regulatory focus, Interacting with Computers, 20, 473-479.

Hassenzahl, M., \& Tractinsky, N. (2006). User experience-A research agenda. Behaviour $\mathcal{E}$ Information Technology, 25, 91-97.

Hong, W., Thong, J. Y. L., \& Tam, K.Y. (2007). How do web users respond to non-banner-ads animation? The effects of task type and user experience. Journal of the American Society for Information Science and Technology, 58, 1467-1482.

Horvitz, E., Apacible, J., \& Koch, P. (2004). BusyBody: Creating and fielding personalized models of the cost of interruption. Proceedings of CSCW, Conference on Computer Supported Cooperative Work.

Internet Advertising Bureau UK. (2004). Interactive audience measurement and advertising campaign reporting and audit guidelines. IABUK Internet Advertising Bureau. http:/ / www.iabuk.net

Internet Advertising Bureau UK. (2008a). Guide to online display advertising (Internet marketing handbook). IABUK Internet Advertising Bureau. http://www. iabuk.net

Lang, A. (2000). The limited capacity model of mediated message processing. Journal of Communication, 50(3), 46-67.

Lapa, C. (2007). Using eye tracking to understand banner blindness and improve website design. Unpublished master's thesis, Golisano College of Computing and Information Sciences, Rochester Institute of Technology. http:/ / hdl.handle.net/1850/4768

Li, H., \& Leckenby, J. (2004). Internet advertising formats and effectiveness. Center for Interactive Advertising. http:/ / www.ciadvertising.org/studies/reports/measurement/ ad_format_print.pdf 
Macias, W. (2003). A preliminary structural equation model of comprehension and persuasion of interactive advertising brand web sites. Journal of Interactive Advertising, 3(2). http://jiad.org/article34

Mack, A., \& Rock, I. (1998). Inattentional blindness. Cambridge, MA: MIT Press.

Mancero, G., Wong, W., \& Amaldi, P. (2007). Looking but not seeing: Implications for HCI. Proceedings of the 14th European Conference on Cognitive Ergonomics: Invent! Explore!, pp. 167-174. Marchionini, G. (1995). Information seeking in electronic environments. Cambridge, UK: Cambridge University Press.

McCoy, S., Everard, A., Polak, P., \& Galletta, D. F. (2007). The effects of online advertising. Communications of the ACM, 50(3), 84-88.

McCrickard, D. S., Catrambone, R., Chewar, C. M., \& Stasko J. T. (2003). Establishing tradeoffs that leverage attention for utility: Empirically evaluating information display in notification systems. International Journal of Human-Computer Studies, 58(5), 547-582.

McCrickard, D. S., \& Chewar C. M. (2003). Attuning notification design to user goals and attention costs. Communications of ACM, 46, 67-72.

McCrickard, D. S., Czerwinski, M., \& Bartram, L. (2003). Introduction: Design and evaluation of notification user interfaces. Int. J. Human-Computer Studies 58(5): 509-514.

Naveh-Benjamin, M., Guez, J., \& Marom, M. (2003). The effects of divided attention at encoding on item and associative memory. Memory \& Cognition, 31, 1021-1035.

Norman, D. (2003). Emotional design: Why we love (or hate) everyday things. New York: Basic Books.

Novak, T. P., Hoffman, D. L., \& Duhachek, A. (2003). The influence of goal-directed and experiential activities on online flow experiences. Journal of Consumer Psychology, 13(1\&2), 3-16.

Online Publisher Association. (2007). OPA Europe Internet Use at Work Media Consumption Study 2007. http:/ / www.opa-europe.org

Pagendarm, M., \& Schaumburg, H. (2001). Why are users banner-blind? The impact of navigation style on the perception of web banners. Journal of Digital Information, 2(1). http://journals.tdl.org/jodi/article/view/jodi-37/38

Patrali, C., Hoffman, D. L., \& Novak, T. P. (2003). Modeling the clickstream: Implications for web-based advertising efforts. Marketing Science, 22(4).

Petty, R., \& Cacioppo, J. T. (1983). Central and peripheral routes to advertising effectiveness: The moderating role of involvement. Journal of Consumer Research, 19, 135-146.

Petty, R. E., \& Caccioppo, J. T. (1986). The elaboration likelihood model of persuasion. In Advances in experimental social psychology (Vol. 19, pp. 123-205). New York: Academic Press.

Reeves, B., \& Nass, C. (1996). The media equation: How people treat computers, television, and new media like real people and places. Cambridge, UK: Cambridge University Press.

Reeves, B., \& Nass, C. (2000). Perceptual bandwidth. Communications of the ACM, 43, 65-70.

Rodgers, S. (2000). The interactive advertising model: How users perceive and process online ads. Journal of Interactive Advertising, 1(1).

Rubin, J., \& Chisnell, D. (2008). Handbook of usability testing (Technical Communication Library, 2nd ed.). New York: Wiley.

Salvucci, D. D. (2001). An integrated model of eye movements and visual encoding. Cognitive Systems Research, 1, 201-220.

Shen, F. (2002). Banner advertisement pricing, measurement, and pretesting practices: Perspectives from interactive agencies. Journal of Advertising, 31, 59-67.

Sicilia, M., \& Ruiz, S. (2007). The role of flow in web site effectiveness. Journal of Interactive Advertising, 8(1).

Simons, D. J., \& Levin, D. T. (1997). Change blindness. In Trends in cognitive sciences (Vol. 1, pp. 261-267). New York: Elsevier. 
Sundar, S. S., \& Kalyanaraman, S. (2004). Arousal, memory, and impression-formation effects of animation speed in web advertising. Journal of Advertising, 33, 7-18.

Sundar, S. S., \& Kim, J. (2005). Interactivity and persuasion: Influencing attitudes with information and involvement. Journal of Interactive Advertising, 5(2). http:/ /jiad.org/article59

Tractinsky, N. (1997). Aesthetics and apparent usability: Empirically assessing cultural and methodological issues. In CHI '97: Proceedings of the SIGCHI conference on Human factors in computing systems (pp. 115-122). New York: ACM.

$\mathrm{Wu}, \mathrm{G}$. (2005). The mediating role of perceived interactivity in the effect of actual interactivity on attitude toward the website. Journal of Interactive Advertising, 5(2).

Yoo, C. Y., Kim, K., \& Stout, P. A. (2004). Assessing the effects of animation in online banner advertising: hierarchy of effects model. Journal of Interactive Advertising, 4(2). http://jiad.org/article49 